\title{
FUNGSI KOMUNIKASI ISLAM DI ERA DIGITAL
}

\author{
QUDRATULLAH \\ Jurusan Komunikasi Penyiaran Islam \\ IAIN Bone \\ Email : qudratullahrustam@gmail.com
}

\begin{abstract}
:
Communication is a very important thing in everyday life. Through communication, there is an interaction between communicator and communicant with the aim of achieving an equation. The communication process can be interpreted as an activity of 'transfer information' or message from the sender of the message as a communicator and to the recipient as a communicant. In the communication process aims to achieve mutual understanding between the two parties involved in the communication process. In the process of communication, the communicator sends messages or information to the communicant as the target of communication. In the communication process, it must work as its function. No exception to Islamic communication. The functions of Islamic communication are very important to be implemented so that communication is carried out not only as a process but communicators and communicants can get a good impact. Islamic communication functions are discussed in several parts, namely: information functions, convincing functions, reminding functions, motivating functions, social functions, guidance functions, satisfaction functions, spiritual, and entertainment functions. In the digital era with the rapid development of media, the function is easily applied because it follows the convenience given to communicators and communicants. But there needs to be limitations that must be made so that the functions of Islamic communication that are applied are able to bring benefits to themselves and society in general and avoid things that are not in accordance with the values of religion and culture adopted.
\end{abstract}

Keywords : Islamic Communication, Function, Digital Era, Media.

\section{PENDAHULUAN}

Pada dasarnya manusia adalah makhluk soisal, makhluk yang membutuhkan bantuan orang lain dalam kehidupannya. Manusia untuk menjalani kehidupan sehari-harinya membutuhkan dan dibutuhkan orang lain. Maka dari itu manusia akan selalu membutuhkan bantuan orang lain dalam hidupnya. Untuk menjaga hubungan tersebut dibutuhkan sebuah komunikasi yang baik antar sesama manusia. Begitu pentingnya komunikasi dalam kehidupan manusia 
sehingga manusia membuat sebuah kesepakatan dalam komunikasi dengan adanya etika dalam berkomunikasi agar tercapainya fungsi-fungsi komunikasi Islam.

Komunikasi Islam merupakan pemikiran komunikasi yang baru muncul dalam akademik sekitar tiga decade belakangan ini. Akhir-akhir ini, komunikasi Islam banyak memperbincangkan tentang fungsi komunikasi Islam serta pendekatan Islam tentang komunikasi.

Titik penting munculnya aktivisme dan pemikiran mengenai komunikasi Islam ditandai dengan terbitnya jurnal "Media, Culture and Society" pada bulan Januari 1993 di London. Ini semakin menunjukkan jati diri komunikasi Islam yang semakin mendapatkan perhatian dan sorotan masyarakat. Tujuan komunikasi Islam sendiri adalah sebagai alternatif, terutama dalam menjunjung tinggi nilainilai komunikasi yang bersesuaian dengan norma-norma keislaman yang member manfaat terhadap kesejahteraan manusia. Fungsi utama komunikasi Islam yaitu untuk mewujudkan persamaan makna, dengan demikian akan terjadi perubahan sikap atau tingkah laku pada masyarakat muslim. ${ }^{1}$

Dalam berkomunikasi hendaklah sesuai dengan kenyataan yang ada. Prinsip etika tersebut sesungguhnya dapat dijadikan sebagai landasan oleh setiap muslim dalam berkomunikasi, baik, baik dalam keseharian maupun dengan aktivitas-aktivitas lainnya. Pada zaman sekarang ini, manusia diharapkan mampu menyesuaikan diri dengan menggunakan media masa sehingga arus informasi Islam atau nilai-nilai kebaikan dapat menyebar di lingkungan masyarakat. ${ }^{2}$

Di era digital, komunikasi islam perlu dijalankan sebagaimana mestinya agar berjalan sesuai dengan koridornya. Perlu diketahui bahwa komunikasi Islam sangatlah penting untuk diterapkan fungsinya dalam kehidupan sehari-hari agar proses komunikasi dapat berjalan sesuai harapan komunikan dan komunikator.

\section{HASIL DAN PEMBAHASAN}

\section{Komunikasi Islam}

Istilah komunikasi atau dalam bahasa Inggris communication berasal dari kata Latin communication, dan bersumber dari kata communis yang berarti sama. Sama di sini yang dimaksud adalah sama makna. Jadi, kalau ada dua orang yang terlibat dalam komunikasi, misalnya dalam bentuk percakapan maka komunikasi akan terjadi atau berlangsung selama ada kesamaan makna mengenai apa yang dipercakapkan. ${ }^{3}$

\footnotetext{
${ }^{1}$ Jamaluddin Budiman, Komunikasi Islam (Jakarta: Academia Press, 2001), h.22.

${ }^{2}$ Djamalul Abidin Ass, Komunikasi dan Bahasa Dakwah (Jakaera: Gema Insani Press, 1996), h. 122.

${ }^{3}$ Onong Uchjana Effendy, Ilmu Komunikasi Teori dan Praktek (Cet. 21; Bandung: PT. Remaja Rosdakarya Offset, 2007), h. 9.
} 
Adapun beberapa definisi komunikasi dari beberapa pakar, sebagai berikut:

1. Hovland

Komunikasi adalah proses mengubah perilaku orang lain (communication is the process modify the behavior of other individuals). ${ }^{4}$

2. Harold Lasswell

(Cara yang paling baik untuk menggambarkan komunikasi adalah denga menjawab pertanyaan pertanyaan berikut) Who Says What In Which Channel To Whom With What Effect? atau Siapa Mengatakan Apa Dengan Saluran Apa Kepada Siapa Dengan Pengaruh Bagaimana? 5

\section{Edwin Emery}

Komunikasi adalah seni menyampaikan informasi ide dan sikap seseorang kepada orang lain. ${ }^{6}$

Dari beberapa definisi komunikasi di atas, maka dapat disimpulkan bahwa komunikasi adalah proses penyampaian informasi kepada kepada orang lain yang memiliki kesamaan makna.

Selain itu, ada juga beberapa unsure komunikasi berdasarkan definisi komunikasi oleh Lasswell, komunikasi yaitu Who Says What In Which Channel To Whom With What Effect? atau Siapa Mengatakan Apa Dengan Saluran Apa Kepada Siapa Dengan Pengaruh Bagaimana ?, maka dapat diturunkan lima unsur komunikasi yang saling bergantung sau sama lain, yaitu :

1. Komunikator (Communicator, source, sender)

Komunikator (Communicator, source, sender) adalah pihak yang mengirim pesan kepada khalayak. Oleh karena itu komunikator juga disebut pengirim, sumber, source, atau encoder. Sebagai pelaku utama dalam proses komunikasi, komunikator memegang peranan yang sangat penting, terutama dalam mengendalikan jalannya komunikasi, dan juga karya ide serta penuh daya kreativitas. ${ }^{7}$

\footnotetext{
${ }^{4}$ Onong Uchjana Effendy, Ilmu Komunikasi Teori dan Praktek (Cet. 21; Bandung: PT. Remaja Rosdakarya Offset, 2007), h. 10.

${ }^{5}$ Deddy Mulyana, Ilmu Komunikasi Suatu Pengantar (Cet. 12; Bandung: PT. Remaja Rosdakarya Offset, 2008), h. 69.

${ }^{6}$ Tommy Suprapto, Pengantar Ilmu Komunikasi dan Peran Manajemen dalam Komunikasi (Cet. 1; Yogyakarta: Caps, 2011), h. 5.

${ }^{7}$ Hafied Cangara, Pengantar Ilmu Komunikasi (Edisi: 2; Jakarta: Rajawali Pers, 2012), h. 99 .
} 


\section{Pesan (Message)}

Pesan (Message) adalah apa yang dikomunikasikan oleh sumber kepada penerima. Pesan merupakan sekelompok pesan verbal dan atau nonverbal yang mewakili perasaan, nilai, gagasan atau maksud sumber. Pesan mempunyai tiga komponen: makna, simbol yang digunakan untuk menyampaikan makna, dan bentuk atau organisasi pesan. ${ }^{8}$

\section{Media (Channel, Media)}

Media (Channel, Media) adalah alat atau sarana yang digunakan untuk menyampaikan pesan dari komunikator kepada khalayak. Ada beberapa pakar psikologi yang memandang bahwa dalam komunikasi antarmasnusia, media yang paling dominan dalam berkomunikasi adalah pancaindra manusia, seperti mata dan telinga. ${ }^{9}$

\section{Komunikan (Communicant, communicate, receiver, recipient)}

Komunikan (Communicant, communicate, receiver, recipient) adalah orang yang menerima pesan dari sumber. Berdasarkan pengalaman masa lalu, rujukan nilai, pengetahuan persepsi, pola piker dan perasaannya, penerima pesan ini menerjemahkan atau menafsirkan seperangkat symbol verbal atau nonverbal yang ia terima menjadi gagasan yang dapat ia pahami. $^{10}$

\section{Efek (Effect, impact, influence)}

Efek (Effect, impact, influence) adalah apa yang terjadi pada penerima setelah ia menerima pesan tersebut, misalnya penambahan pengetahuan (dari tidak tahu menjadi tahu), terhibur, perubahan sikap (dari tidak setuju menjadi setuju), perubahan keyakinan, perubahan perilaku. ${ }^{11}$ Sedangkan Islam secara bahasa berarti tunduk, patuh, dan damai. Islam menurut istilah adalah nama agama yang diturunkan Allah Swt untuk membimbing manusia ke jalan yang benar dan sesuai fitrah kemanusiaan. Islam adalah agama dakwah, artinya agama yang selalu mendorong pemeluknya untuk senantiasa aktif melakukan kegiatan dakwah. ${ }^{12}$ Sehingga dapat disimpulkan bahwa komunikasi Islami adalah proses penyampaian pesan

\footnotetext{
${ }^{8}$ Deddy Mulyana, Ilmu Komunikasi Suatu Pengantar (Cet. 12; Bandung: PT. Remaja Rosdakarya Offset, 2008), h. 70.

${ }^{9}$ Hafied Cangara, Pengantar Ilmu Komunikasi (Edisi: 2; Jakarta: Rajawali Pers, 2012), h. 137.

${ }^{10}$ Deddy Mulyana, Ilmu Komunikasi Suatu Pengantar (Cet. 12; Bandung: PT. Remaja Rosdakarya Offset, 2008), h. 71.

${ }^{11}$ Deddy Mulyana, Ilmu Komunikasi Suatu Pengantar (Cet. 12; Bandung: PT. Remaja Rosdakarya Offset, 2008), h. 71.

${ }^{12}$ Munir, Metode Dakwah (Jakarta: Kencana, 2009), h. 4
} 
antara manusia yang didasarkan pada ajaran Islam. Artinya bahwa komunikasi Islami adalah cara berkomunikasi yang bersifat Islami (tidak bertentangan dengan ajaran Islam). Dengan demikian pada akhirnya terjadi juga konvergensi (pertemuan) antara pengertian komunikasi Islam dengan komunikasi Islami. Boleh dikatakan, komunikasi Islami adalah implamentasi (cara melaksanakan) komunikasi Islam. ${ }^{13}$ Oleh karena itu, komunikasi islam dan komunikasi secara umum sapat dibedakan dari tujuannya. Komunikasi islam bertujuan menyampaikan seuah pesan atau informasi berlandaskan Al-Qur'an dan hadist. Sedangkan komunikasi secara umum bertujuan untuk menemukan persamaan secara umum.

\section{Fungsi-Fungsi Komunikasi Islam}

\section{Fungsi Informasi}

Informasi adalah kehidupan, karena sejak lahir seluruhperangkat untuk menyerap inforamsi seperti mata, telinga dan hati sebgai perangkat utama kehidupan sudah terpasang dan siap difungsikan. Selain alat penangkap informasi, Allah juga sudah menyiapkan perangkat untuk menyampaikan kembali informasi yang telah ditangkap kepada orang lain. Alat itu adalah lidah, dua bibir dan segala hal yang terkait.

Prinsip dasar agama Islam dalam menyebarkan informasi adalah penutup rapat informasi yang tidak baik yang terkait dengan orang lain, terutama yang terkait dengan masalh pribadi. Islam melarang namimah atau mengungkapkan kejelekan orang lain, dan mengategorikan perbuatan ini sebagai salah satu dosa besar. Islam melarang orang yang bermimpi jahat untuk menyampaikan isi mimpinya kepada orang lain. Bahakan orang yang bangga menyampaikan informasi tentang kejahatan yang dia lakukan termasuk orang yang tidak diampuni dosanya oleh Allah. ${ }^{14}$

Pandangan Islam menyebutkan informasi adalah pintu awal seseorang memiliki karakter tertentu, baik atau buruk. Ibnu Qayyim mengatakan bahwa karaktertidak terbentuk otomatis, tetapi melalui tahapan-tahapan. Pembentua karakter dimulai dengan langkah mengumpulkan informasi tentang makna pesan, lalu terbentuk persepsi, lalu muncul keinginan dan akhirnya melahirkan perbuatan. Perbuatan yang dilalukan secara berulang akan melahirkan karakter. Baik tidaknya suatu karakter tergantung dari input informasi yang masuk. ${ }^{15}$

Mengingat pentingnya infomasi dalam kehidupan manusia, maka Islam

\footnotetext{
${ }^{13}$ Andi Abdul Muis, Komunikasi Islam (Bandung: Remaja Rosdakarya, 2001), h. 65-66

${ }^{14}$ Hendri, Komunikasi Islam (Jakarta: PT. Fajar Interpratama Mandiri, 2005), h. 21.

${ }^{15}$ Harjani Hefni, Komunikasi Islam (Pontianak, IAIN Pontianak Press, 2014), h. 32.
} 
melarang keras sumatnya utuk berdusta, karena dusta akan menciptakan rusaknya persepsi seseorang terhadap orang lain atau terhadap sesuatu dan menyeret pelakunya untuk masuk neraka. Informasi saat ini menjadi sebuah kebutuhan yang sangat penting bagi masyarakat. Informasi bisa saja dikatakan sebagai kebutuhan yang tidak lagi terpisahkan dari kehidupan masyarakat. Seiring perkembangan teknologi informasi dan komunikasi, informasi sangat mudah diperoleh oleh masyarakat. Baik secara lisan maupun melalui media massa terutama media online yang memudahkan masyarakat dalam mengakses informasi tanpa mengenal tempat dan waktu. Yang jelas, selalu didukung oleh perangkat teknologi informasi.

\section{Fungsi Meyakinkan}

Fungsi meyakinkan artinya membuat ide, pendapat dan gagasan yang kita miliki bisa diterima oleh orang lain dengan senang hati dan tidak terpaksa. Bahkan bukan sekedar menerima dengan sukarela, mereka yang merasa mantap dengan penjelasan tersebut bisa menjadi pendukung ide itu.

Fungsi meyakinkan dalam komunikasi Islam bisa dicapai di antaranya dengan metode hiwar (dialog) dan jidal (debat). Hiwar dilakukan dengan suasana santai, saling mengemukakan pendapat dengan tenang, mungkin didalamnya juga terjadi tarik ulur dan akhirnya berujung kepada suatu kesepakatan mendukung ide bersama atau salah satu ide yang lebih baik. Adapun jidal biasanya lebih seru, kadang-kadang sampai panas dan masing-masing pada ngotot dengan pendapatnya. Orang yang menyampaikan ide cemerlang dengan alasan-alasan dan logika yang kuat biasanya menjadi pemenang dan idenya akan dijadikan rujukan. $^{16}$

\section{Fungsi Mengingatkan}

Lupa adalah sifat yang tidak bisa berpisah dari manusia. Sifat ini sudah ada sejak adanya manusia pertama, Adam as. Ibnu Mandzur dalam Lisan al-Arab mengatakan bahwa di antara rahasia penamaan manusia dengan istilah insan karena manusia memiliki sifat pelupa. Pendapat Ibnu Mandzur itu disandarkan kepada pemahaman Ibnu Abbas tentang QS. Thaha: 115 yang mengisahkan tentang sebab Adam melanggar perintah Allah untuk tidak memakan buah pohon al-Khuldi ternyata memakan buah tersebut dikarenakan lupa. Lupa didefinisikan sebagai ketidakmampuan mengingat kembali suatu hal yang diperlukan pada saat yang di inginkan. Ada banyak faktor yang menjadi penyebab lupa dan kita memerlukan metode untuk mencegah agar kita tidak mudah lupa atau untuk memperkuat ingatan. ${ }^{17}$

\footnotetext{
${ }^{16}$ Hendri, Komunikasi Islam (Jakarta: PT. Fajar Interpratama Mandiri, 2005), h. 23.

${ }^{17}$ Harjani Hefni, Komunikasi Islam (Pontianak, IAIN Pontianak Press, 2014), h. 33.
} 
Di antara masalah yang paling banyak dilupakan dan dilalaikan oleh manusia adalah masalah agama. Itulah sebabnya kenapa Islam memerintahkan kepada penganutnya untuk mengulang-ulang suatu ucapan atau perbuatan, terutama dalam masalah-masalah krusial. Dakwah agama adalah salah satu cara untuk menginformasikan kepada manusia agar selalu ingat tentang tujuan hidup dan bagaimana mengisi hidup sebenarnya. Dan metode komunikasi dalam dakwah yang paling cocok untuk merealisasikan fungsi mengingatkan adalah metode tadzkir dan indzar.

\section{Fungsi Memotivasi}

Manusia dalam hidupnya memerlukan charge karena semangat hidup manusia secara umum tidak stabil. Charge itu disebut dengan motivasi.

Ada beberapa kondisi yang menyebabkan mtoivasi hidup seseorang menjadi tidak stabil. Menurut al-Kirmani, penurunan kualitas manusia itu bsa disebabkan oleh tiga faktor, yaitu : jiwa, fisik dan eksternal. Adapun jiwa tergantung dari kekuatan yang dimiliki manusia yaitu kekuatan akal, kekuatan marah, dan kekuatan syahwat. Hamm (galau dengan masa depan) dan Hazn (sedih dengan masa lalu) adalah dua penyakit yang menyerang akal. Jubn (pengecut) adalah penyakit yang menyerang kekuatan marah. Sedangkan Bukhl (bakhil) adalah penyakit yang menyerang kekuatan syahwat. Adapun yang melemahkan kekuatan fisik adalah penyakit 'Ajaz (merasa tidak punya potensi) dan Kasal (malas, padahal mampu). Sedangkan pengaruh eksternal yang membuat manusia kehilangan potensi adalah lilitan hutang dan berada dibawah tekanan orang lain. Hutang membuat orang menjadi lemah, dan berada dibawah tekanan orang lain membuat kehilangan harga diri. ${ }^{18}$

Mengucapkan secara berulang-ulang setiap pagi dan petang tentang halhal yang hendak kita hindari atu hal-hal yang seharusnya kita lakukan adalah metode komunikasi antara manusia dengan Tuhannya dan dengan dirinya sendiri untuk membuang penyakit-penyakit mental yang ada di dalam dirinya yang membuatnya terbelenggu dan menumbuhkan nilai-nilai positif sehingga dia bisa terbang bebas merealisasikan mimpinya.

Metode memotivasi diri sendiri adalah metode yang paling ideal. Metode ini praktis, murah dan mudah, tetapi dahsyat hasilnya. Selain metode memotivasi diri sendiri, manusia juga bisa termotivasi jika mendapat suntikan motivasi dari orang lain. Komunikasi adalah salah satu cara untuk menyuntikkan motivasi

\footnotetext{
${ }^{18}$ Harjani Hefni, Komunikasi Islam (Pontianak, IAIN Pontianak Press, 2014), h. 35.
} 
kepada orang lain. Metode yang paling cocok untuk menyuntikkan motivasi dalam komunikasi Islam adalah metode tabligh dan tabsyir. ${ }^{19}$

\section{Fungsi Sosialisasi}

Manusia dalam hidupnya tidak lepas dari berbagai macam kebutuhan. Banyak teori yang menjelaskan tentang teori kebuthan, dan diantara yang paling terkenal adalah teori Maslow. Dalam bukunya "Motivation and Personality", Maslow memberikan lima jenjang kebutuhan pokok manusia.

Di antara lima jenjang kebutuhan itu, kebutuhan untuk disayangi oleh orang di sekitarnya ditempatkan oleh Maslow pada urutan ketiga. Apapun komentar orang tentang teori ini, kebutuhan kita semua untuk bisa diterima dan dihargai. Tidak mungkin sosialisasi dilahirkan tanpa komunikasi. Dalam alQur'an, fungsi sosialisasi disebut dengan ta'aruf. Dan di dalam hadis, Rasulullah menyebutnya dengan mukhalathah. ${ }^{20}$

Ta'aruf adalah salah satu metode komunikasi yang efektif. Dengan ta'aruf, hubungan antar manusia menjadi tersambung. Ta'aruf yang baik akan melahirkan keinginan untuk saling membantu bahkan sampai ke tingkat saling mengayomi. ${ }^{21}$

\section{Fungsi Bimbingan}

Di antara fungsi komunikasi adalah untuk membimbing manusia. Tidak semua kita mampu mebaca kemampuan kita sendiri, dan tidak semua kita mampu menyelesaikan masalah kita sendiri. Padahal hidup tidak pernah sepi dari masalah. Disinilah manusia memerlukan orang lain untuk membimbingnya mencari solusi atau mengarahkannya ke tempat yang tepat. Dalam istilah komunikasi Islam, fungsi bimbingan ini disebut dengan Irsyad.

Ada empat fokus utama aktivitas komunikasi dalam membimbing seseorang : pertama, membimbing orang untuk melakukan perbuatan baik dan menangkal mereka untuk melakukan perbuatan yang negatif; kedua, memperbaiki atau memulihkan kondisi mereka yang sudah rusak; ketiga, mengarahakan orang untuk menemuukan potensi yang mereka miliki; dan keempat, mengembangkan potensi manusia agar lebih maksimal.

Manusia dilahirkan dalam keadaan fitrah, tetapi berpotensi menjadi rusak karena dalam diri manusia terdapat sifat fujur. Bimbingan akan berfungsi sebagai pencegahan jika dilakukan sejak dini sebelum seorang anak terkontaminasi dengan lingkungannya. ${ }^{22}$

Secara umum, bimbingan diberikan dalam bentuk komunikasi antarpersonal atau komunikasi kelompok kecil. Komunikasi antarpersonal

\footnotetext{
${ }^{19}$ Hendri, Komunikasi Islam (Jakarta: PT. Fajar Interpratama Mandiri, 2005), h. 23.

${ }^{20}$ Jamaluddin Budiman, Komunikasi Islam (Jakarta: Academia Press, 2001), h.48.

${ }^{21}$ Harjani Hefni, Komunikasi Islam (Pontianak, IAIN Pontianak Press, 2014), h. 38.

${ }^{22}$ Harjani Hefni, Komunikasi Islam (Pontianak, IAIN Pontianak Press, 2014), h. 40.
} 
menjadi pilihan utama dalam bimbingan karena setiap orang memiliki permasalahan yang berbeda dengan orang lain. Bimbingan bisa dilakukan dalam kelompok kecil jika orang-orang yang berkumpul dalam kelompok tersebut adalah orang-orang yang memiliki permasalahan yang relatif sama. ${ }^{23}$

Bimbingan bisa dilakukan dengan melakukan percakapan pribadi, dialog langsung, dan tatap muka dengan orang yang dibimbing, bisa dilakukan dengan home visit untuk mengetahui kondisi rumah dan lingkungan yang mempengaruhinya, atau berkunjung ke tempat kerjanya dan melakukan percakapan individual sekaligus mengamati kerja klien di lingkungannya.

\section{Fungsi Kepuasan Spiritual}

Manusia terbentuk dari dua unsur, yang keduanya memiliki kebutuhan yang harus dipenuhi. Tubuh memerlukan makanan, pakaian, tempat tinggal dan segala hal yang mendukung keselamatannya. Sedangkan kebutuhan ruh adalah berkomunikasi dengan Allah, Sang Pencipta. Ketika ruh bersambung dengan Sang Penciptanya, hati menjadi tenang. Al-Qur'an menyatakan bahwa sumber ketenangan hati adalah dzikir. Di antara metode memuaskan spiritual adalah dengan memberikan mau'idzah dan nasihat kepada mereka. ${ }^{24}$

\section{Fungsi Hiburan}

Dalam hidup ini, kita hanya akan berhadapan dengan dua kemungkinan, yaitu bahaga atau sedih. Tidak ada orang yang seumur hidupnya hanya merasakan kebahagiaan. Suatu saat dia akan mengalami masa-masa berat dalam hidupnya. Tetapi tidak ada juga orang semasa hidupnya hanya merasakan penderitaan, pasti ada waktu-waktu dia bisa tertawa dan mengalami masa-masa bahagia. Ketika mendapatkan kebahagiaan, Islam mengajarkan kepada penganutnya agar mengucapkan syukur atas nikmat yang telah didapat. Dan kepada saudranya yag mengetahui temannya mendapatkan nikmat dianjurkan untuk menambah rasa bahagia saudaranya dengan mencupkan selamat kepadanya. ${ }^{25}$

Selain rasa bahagia, kadang-kadang kita juga diselimuti oleh rasa takut. Takut kehilangan orang yang dicintai, takut dengan ketidak jelasan masa depan, takut kehilangan pekerjaan, takut kehilangan harta, dan seterusnya. Semua kita pasti merasa lelah. Kadang harus berhadapan dengan kesulitan, diuji dengan berbagai kasus, bahkan tidak jarang harus menderita.

Dalam kondisi seperti itu, hati kita sangat perlu kepada hiburan. Hati yang terhibur akan membuat rasa takut menjadi hilang, lelah akan hilang, derita

\footnotetext{
${ }^{23}$ Jamaluddin Budiman, Komunikasi Islam (Jakarta: Academia Press, 2001), h.49.

${ }^{24}$ Harjani Hefni, Komunikasi Islam (Pontianak, IAIN Pontianak Press, 2014), h. 40-41.

${ }^{25}$ Harjani Hefni, Komunikasi Islam (Pontianak, IAIN Pontianak Press, 2014), h. 41.
} 
terobati, dan kondisi kita menjadi segar kembali.

\section{Penerapan Fungsi Komunikasi Islam di Era Digital}

Keberadaan fungsi komunikasi Islam diharapkan mampu dilakukan seiring perkembangan teknologi informasi dan komunikasi atau disebut era digital.

Fungsi komunikasi Islam menjadi bagian terpenting yang bukan hanya menjadi penyeimbang komunikasi pada umumnya tetapi juga sebagai solusi dari problematika komunikasi di era digital.

Komunikasi Islam seharusnya menjadi solusi dari aspek fungsi informasi yang saat ini banyak mengalami permasalahan-permasalahan dengan memunculkan berbagai konflik yang terjadi di masyarakat. Fungsi informasi komunikasi Islam diharapkan mampu menawarkan informasi-informasi yang mengandung nilai-nilai kedamaian, kebaikan dan kebahagaian bagi masyatakat. Dengan begitu akan terwujud masyarakat yang harmonis di kalangan masyarakat era digital. Seperti diketahui, informasi-informasi hoaks berputar di sekeliling masyarakat mengancam kemarmonisan masyarakat. Maka dari itu, nilai-nilai perdamaian, toleransi, kebaikan dan informasi yang mengandung unsur kegembiraan lebih dikedepankan lagi.

Fungsi meyakinkan di era digital dalam komunikasi Islam dilakukan dengan berdialog dan berdiskusi antara komunikator dan komunikan. Dialog lebih ditujukan kepada khalayak yang telah memiliki kesamaan landasan berpikir rasional terhadap isu tertentu sehingga mencapai kesepakatan bersama. Sedangkan diskusi dilakukan lebih ditujukan kepada khalayak yang telah memiliki landasan berpikir rasional terhadap isu tertentu sehingga lebih isi diskusi lebih mendalam dan juga alot. Meski dilakukan di media digital, hal tersebut tidaklah sulit karena unsur umpan balik akan lebih efektif dibanding dengan media televisi, radio maupun media cetak. Meyakinkan khalayak dilakukan dengan memberikan ide ataupun gagasan sehingga ada hasil yang diperoleh dari komunikasi yang dibangun. Dialog dan diskusi yang dilakukan bukan semata-mata untuk mencari kemenangan tetapi mencari kebenaran dari masalah yang dibahas.

Komunikasi Islam juga tak terlepas dari fungsi mengingatkan dan fungsi sosialisasi serta fungsi bimbingan. Dengan keberadaan media digital, akan lebih mudah mengingatkan khalayak dengan cara-cara yang lebih praktis tetapi perlu memperhatikan psikologi dari komunikan. Perlu penerapan fungsi mengingatkan ketika melihat pengguna media sosial melakukan hal-hal yang tidak sesuai dengan nilai-nilai agama dan budaya yang diterapkan dalam lingkungan. Selain itu, fungsi memotivasi tidak kalah pentingnya diterapkan di era digital. Bisa saja fungsi tersebut dilakukan dengan memotivasi langsung para pengguna media digital dengan melakukan komunikasi antarpribadi melalui media sosial atau menyebarkan pesan-pesan motivasi di media sosial baik melalui tulisan opini, tulisan di media sosial atau hasil rekaman motivasi di You tube, instagram 
maupun media lainnya. Pengarahan akan lebih mudah dilakukan melalui media digital. Mengarahakan kepada hal yang baik hingga apada memantik potensi yang dimiliki komunikan sehingga dapat direalisasikan dan diaplikasikan dalam kehidupan bermasyarakat.

Fungsi kepuasan spiritual juga mudah diterapkan dengan adanya informasi dan tayangan-tayangan keagamaan yang disajikan di media massa. Sama halnya dengan fungsi hiburan, hal tersebut juga sangat mudah diperoleh dengan kebebasan yang ditawarkan media. Hanya saja perlu batasan-batasan yang harus diketahui oleh masyatakat bagaimana memperoleh kepuasan spiritual yang sesuai ajaran agama dan jauh dari sifat-sifat radikal. Begitupun dengan fungsi hiburan, perlu juga difilter agar dapat menentukan hiburan yang bermanfaat dan hiburan yang hanya berlalu begitu saja tanpa ada hikmah yang diperoleh.

\section{SIMPULAN}

Komunikasi Islam memiliki banyak fungsi dalam penggunaannya oleh masyarakat luas. Beberapa fungsi komunikasi Islam adalah fungsi informasi diambil dari istilah naba' dan khabar. Fungsi meyakinkan diambil dari metode hiwar dan jidal. Fungsi mengingatkan diambil dari metode tadzkir dan indzar. Fungsi memotivasi diperoleh dari metode tabligh dan tabsyir. Fungsi sosial di peroleh dari dari metode ta'aruf. Fungsi bimbingan dari metode irsyad dan wasiat. Fungsi kepuasan spiritual dari mau'idzah dan nasihat, dan terakhir fungsi hiburan diambil dari istilah idkhal al-surur. Di era digital, fungsi tersebut dengan mudah diterapkan karena mengikuti kemudahan yang diberikan kepada komunikator dan komunikan. Namun perlu adanya batasan-batasan yang harus dilakukan agar fungsi-fungsi komunikasi Islam yang diterapkan mampu membawa manfaat kepada diiri sendiri dan masyarakat secara umum dan terhindar hari hal-hal yang tidak sesuai dengan nilai-nilai agama dan budaya yang dianut.

\section{DAFTAR PUSTAKA}

Ass, Djamalul Abidin. Komunikasi dan Bahasa Dakwah. Jakaera. Gema Insani Press. 1996.

Budiman, Jamaluddin. Komunikasi Islam. Jakarta. Academia Press. 2001.

Cangara, Hafied. Pengantar Ilmu Komunikasi. Edisi. 2. Jakarta. Rajawali Pers. 2012. 
Effendy, Onong Uchjana. Ilmu Komunikasi Teori dan Praktek. Cet. 21. Bandung. PT. Remaja Rosdakarya Offset. 2007.

Hefni, Harjani. Komunikasi Islam. Pontianak. IAIN Pontianak Press. 2014.

Hendri. Komunikasi Islam. Jakarta. PT. Fajar Interpratama Mandiri. 2005.

Muis, Andi Abdul. Komunikasi Islam. Bandung. Remaja Rosdakarya. 2001.

Mulyana, Deddy. Ilmu Komunikasi Suatu Pengantar. Cet. 12. Bandung. PT. Remaja Rosdakarya Offset. 2008.

Munir. Metode Dakwah. Jakarta: Kencana. 2009.

Suprapto, Tommy. Pengantar Ilmu Komunikasi dan Peran Manajemen dalam Komunikasi. Cet. 1. Yogyakarta. Caps. 2011. 